\title{
A Histomorphological Study on the Olfactory Bulb of Diabetic Albino Rats
}

\author{
Muhamed Faizal, Aijaz Ahmed Khan* \\ Department of Anatomy, Jawaharlal Nehru Medical College, Aligarh Muslim University, Aligarh, India \\ Email address: \\ aijazahmedkhan7@live.com (A. A. Khan) \\ ${ }^{*}$ Corresponding author
}

\section{To cite this article:}

Muhamed Faizal, Aijaz Ahmed Khan. A Histomorphological Study on the Olfactory Bulb of Diabetic Albino Rats. International Journal of Clinical and Experimental Medical Sciences. Vol. 3, No. 4, 2017, pp. 43-56. doi: 10.11648/j.ijcems.20170304.12

Received: July 31, 2017; Accepted: August 18, 2017; Published: September 26, 2017

\begin{abstract}
Long standing hyperglycemia is generally associated with a decline in the chemical senses including smell due to its unfavorable destructive effects on the small sized neurons of the Olfactory bulb (OB). Accordingly, the current study was aimed to analyze the effect of experimental hyperglycemia on $\mathrm{OB}$ of albino rats. To detect a possible change on the olfactory bulb during hyperglycemia, 36 albino rats were divided into six groups of six rats each and were designated as control, two week, one month, two month, four month and six month respectively. Diabetes was induced with single dose of streptozotocin (STZ-60 mg/kg, IP). The inductions of diabetes were confirmed by measuring the blood glucose levels in the tail blood with a Glucometer. At the end of each experimental period animals were euthanized by deep ether anesthesia and blood samples were collected by direct puncture of heart for biochemical analysis. Animals were perfused with Karnovsky fixative. After two days tissue specimen were collected and processed for light microscopic studies. Biochemical analysis of serum revealed increased serum creatinine and reduced serum total protein. Histopathology and histomorphometry of OB revealed that the progressively increasing duration of hyperglycemia was associated with noticeable decreased diameter of OB glomeruli, decrease diameter of mitral cells and thickening of supporting connective tissue around the OB and blood vessels. It is concluded that the association of the long-standing hyperglycemia with frequent occurrence of hypercellular glomeruli and misplaced mitral cells, decreased diameter of OB glomeruli and mitral cells, subtle laminar disarray and added deposition of collagen fibers around $\mathrm{OB}$ and blood vessels appear to be important contributing factors responsible for the derangement of olfactory function in diabetics.
\end{abstract}

Keywords: Collagen, Diabetes, Glomeruli, Mitral Cells, Olfactory Bulb, STZ-Induced

\section{Introduction}

Diabetes mellitus is a group of metabolic disorders characterized by a chronic hyperglycemic condition resulting from defects in insulin secretion, insulin action or both [1]. In hyperglycemia, oxidative stress plays a central role in cellular injury through specific mechanism of superoxide production leading to insulin resistance, beta cell dysfunction, and impaired glucose tolerance leading to high risk of diabetic complications [2, 3]. High neuronal glucose levels after persistent hyperglycemia leads to glucose neurotoxicity [4] and prolonged high intracellular glucose in neurons directed to a wide range of functional and structural disorders in various region of nervous system [5]. High cytosolic oxidative stress, due to insulin resistance and insulin deficiency, could be important contributing factors in the development of hyperglycemia-induced olfactory dysfunction $[6,7]$. Oxidative stress has been shown to cause mitochondrial dysfunction which is followed by neuronal apoptosis [8]. Smell and taste are essential in selection and enjoyment of nutrition and food $[9,10]$. The olfactory bulb is one of the elongated structures located above cribriform plate of ethmoid bone having collection of olfactory nerve cells that receives impulses from the olfactory nerves of the nasal mucosa and continues as the olfactory tract [11]. Pathological changes in OB result in increased taste dissatisfaction [12]. Previous studies have reported olfactory dysfunction in individuals with diabetes mellitus, but the etiology is unknown and researcher suggested that the changes were 
associated with macro vascular disease, such as ischemia to the olfactory area, impact negatively on olfactory ability [13] and impaired ability to sense glucose [10]. Olfactory dysfunction has been reported in association with macro vascular complication to olfactory area and ageing [13]. However, clear pathology and clinical significance of olfactory dysfunction in the form of anosmia in relation to the chronic diabetes remains unclear [14].

Many other studies showed that diabetic patients have increased odor detection threshold, decreased odoridentification ability, and increased risk of anosmia $[14,15$, and 16]. Another study observed that the diabetes leads to loss of olfactory sensory neurons with accompanying reduced olfactory discrimination [17]. Other researchers [18, 19] have tried to demonstrate abnormalities in different lamina of olfactory bulb and nerve fibers without using any special stain. Therefore, the current study is aimed at demonstrating these and possibly other changes in the arrangement of glomeruli, mitral cells, nerve fibres and laminar structure by using special staining for collagen staining (PSR) and myelin (LFB) with CV staining in conjunction with histopathological, histomorphological and biochemical parameters in experimentally induced diabetic rats after $2 \mathrm{~W}, 1 \mathrm{M}, 2 \mathrm{M}, 4 \mathrm{M}$ and $6 \mathrm{M}$ periods.

\section{Material and Methods}

\subsection{Animal Preparation}

After approval from Institutional Animal Ethics Committee (No: 9025/2014) the present work was carried out 36 albino rats of either sex weighing approximately $250 \mathrm{~g}$ obtained from central animal house, AMU, Aligarh. Prior to commencement of the experiments, all animals were placed to clean well ventilated and properly maintained new environmental condition for a period of one week were supplied standard pellet diet and water ad libitum and maintained on a 12/12 h light/dark cycle.

\subsection{Experimental Design}

A total number of 36 animals were divided into following six groups having six rats in each group: (1) Non-diabetic healthy Control, age-matched (2) Diabetic Experimental groups: Two week, (3) One month (4) Two month (5) Four month and (6) Six month.

\subsection{Induction of Diabetes}

After 12 hour fasting, experimental diabetic model was induced by single dose of streptozotocin (STZ) $(60 \mathrm{mg} / \mathrm{kg}$, aqueous sol., I. P). Blood sugar level was monitored with Glucometer (Dr Morepen Gluco One BG03 Blood Glucose Meter) from the blood obtained from lateral tail vein before beginning of experiment and after $2^{\text {nd }}$ day streptozotocin injection. Animals with blood sugar level $250 \mathrm{mg} / \mathrm{dl}$ and above were considered as diabetic. Both body weight and blood glucose levels of all animals in each group were monitored biweekly.

\subsection{Tissue Preparation}

After assigned periods all experimental and age matched control animals were euthanized with over dose of ether general anesthesia and perfusion-fixed with Karnovsky's fixative.

\subsection{Histopathology and Histomorphometry}

Olfactory bulb from both sides were carefully dissected out and processed for paraffin embedding. Five $\mu \mathrm{m}$ thick sections were stained with Hematoxyline \& Eosin (H \& E), Cresyle Violet (CV) and Picro Sirus (PSR). Only H \& E and $\mathrm{CV}$ stained sections were used for measuring glomerular and mitral cell diameter. Random photomicrographs were recorded under $\mathrm{x} 400$ magnification of trinocular microscope (Olympus, BX40, and Japan) by digital camera (Sony 18.2 MP, Japan) and measurements were made by using software Motic image version 2.0. Sufficient numbers of random images were taken in order to get 100 mitral cells having a well defined nucleus visible nucleolus. 100 randomly selected glomeruli having homogeneous central neuropil surrounded by peri-glomerular cells were used for the histomorphometry. Data achieved from these used to calculate the mean diameter of glomeruli and mitral cells in different groups.

\subsection{Biochemical Estimation and Analysis}

Blood glucose levels were measure from lateral tail vein blood at biweekly interval with the help of Glucometer. At the end of each study period blood samples were obtained from direct puncture of heart and collected into sterilized plastic vials. Samples were allowed to clot, centrifuged at $2500 \mathrm{rpm}$ for 30 minutes, the serum was separated and stored in sterile plastic vials and subsequently assayed for serum total protein content and serum creatinine level by using Avantor Benesphera ${ }^{\mathrm{TM}}$ clinical chemistry Analyzer C61.

\subsection{Statistical Analysis}

The data related to diameter of glomeruli as well as mitral cells, serum total proteins and serum creatinine level were statistically analyzed and the significance calculated using one way 'ANOVA' followed by Tukey's test. All numerical values were expressed as Mean $\pm \mathrm{SD}$ and the value of $\mathrm{P}<0.05$ was considered as statistically significant.

\section{Results}

\subsection{General Observations}

During the experimental period, STZ-injected rats showed classical clinical manifestations of diabetes such as polydipsia, polyuria and polyphagia.

\subsection{Body Weight}

It was observed that the mean body weights of all diabetic groups reduced compared to age-matched control group 
during experimental period. However the changes compare between age matched control and $2 \mathrm{~W}$ diabetic group were statistically not significant $(>0.05)$ but the reduction was significant $(\mathrm{P}<0.05)$ in all remaining diabetic groups as compare with age-matched controls.

\subsection{Blood Glucose Level}

After 48 hours of induction the blood sugar level in all diabetic groups often remained above $500 \mathrm{mg} / \mathrm{dl}$ which remained significantly $(\mathrm{P}<0.01)$ high throughout the experimental period as compared with the age-matched controls.

\subsection{Microscopic Observation}

\subsubsection{Histopathology}

In $\mathrm{H} \& \mathrm{E}$ and Cresyl violet -stained sections of the olfactory bulb laminar organization of both control and diabetic groups showed the same basic cellular heterogeneous architecture, having six concentric layers from outside to inside: olfactory nerve layer (ONL), glomerular layer (GL), external plexiform layer (EPL), mitral cell layer (MCL), internal plexiform layer (IPL) and granular cell layer (GCL). In general, the location and laminar arrangement of right and left OBs were almost identical in all groups. However, over all the left side OB appeared smaller in all dimensions along with the reduction of laminar thickness in all groups as compared to right $\mathrm{OB}$ possibly reflecting right/left asymmetry (Figure 1). The ONL contained unmyelinated axons of the olfactory neurons and occasional aggregation of less organized supporting cells. In the current study, disturbed architecture of the olfactory bulb was observed with subtle alteration of normal laminar organization in $4 \mathrm{M}$ and $6 \mathrm{M}$ diabetic groups (Figure 2). In $\mathrm{CV}$ and $\mathrm{H} \& \mathrm{E}$ stained sections GL revealed different sized glomeruli as well defined areas; each of the typical glomerulus was surrounded by juxtaglomerular neurons where neuronal cell bodies were not observed inside the glomerulus. Poorly organized glomeruli were clearly observed in $4 \mathrm{M}$ and $6 \mathrm{M}$ diabetic group as compared to all other groups (Figure 2). Atypical hypercellular glomeruli as well as multilayered glomeruli were observed in $2 \mathrm{M}$ onwards diabetic groups (Figure 3B, $3 \mathrm{C})$. The EPL consisted of nerve fibers and glial cells. In the current study all diabetic groups revealed rather atypical position of mitral cells extending into EPL and GL and in one sample of $1 \mathrm{M}$ (Figure 3A). Deep to EPL narrow MCL showed cell bodies of mitral cells, inter neurons and glia which are a discontinuous, widely spaced and arranged usually in single row. Mitral cells in MCL had Nissl substance in the cell body, had euchromatic nuclei and prominent nucleoli. In all groups the MCL could not be discriminated throughout from IPL. In $4 \mathrm{M}$ and $6 \mathrm{M}$ diabetic group, the mitral nerve cells appeared distorted, smaller; shrunken and with some having perineuronal spaces (Figure 4). Misplaced mitral cells were commonly seen in all groups, but were more clearly visible in $1 \mathrm{M}$ and $2 \mathrm{M}$ diabetic group (Figure 3). Lipofuscin pigments could not be observed even in advanced diabetic group (Figure 5). IPL did not reveal any remarkable change. GCL consists of numerous small granule nerve cells. In $2 \mathrm{M}, 4 \mathrm{M}$ and $6 \mathrm{M}$ experimental groups, disorganization with loss of normal arrangement of the GCL as compared with age-matched control was noticed. The intra-bulbar capillaries were seen all laminae of OB. In control group, the connective tissue around the olfactory bulb, nerve fibers and blood vessels had fewer collagen fibres. However in $6 \mathrm{M}$ diabetic group the collagen fibres revealed added thickening (Figure 6).

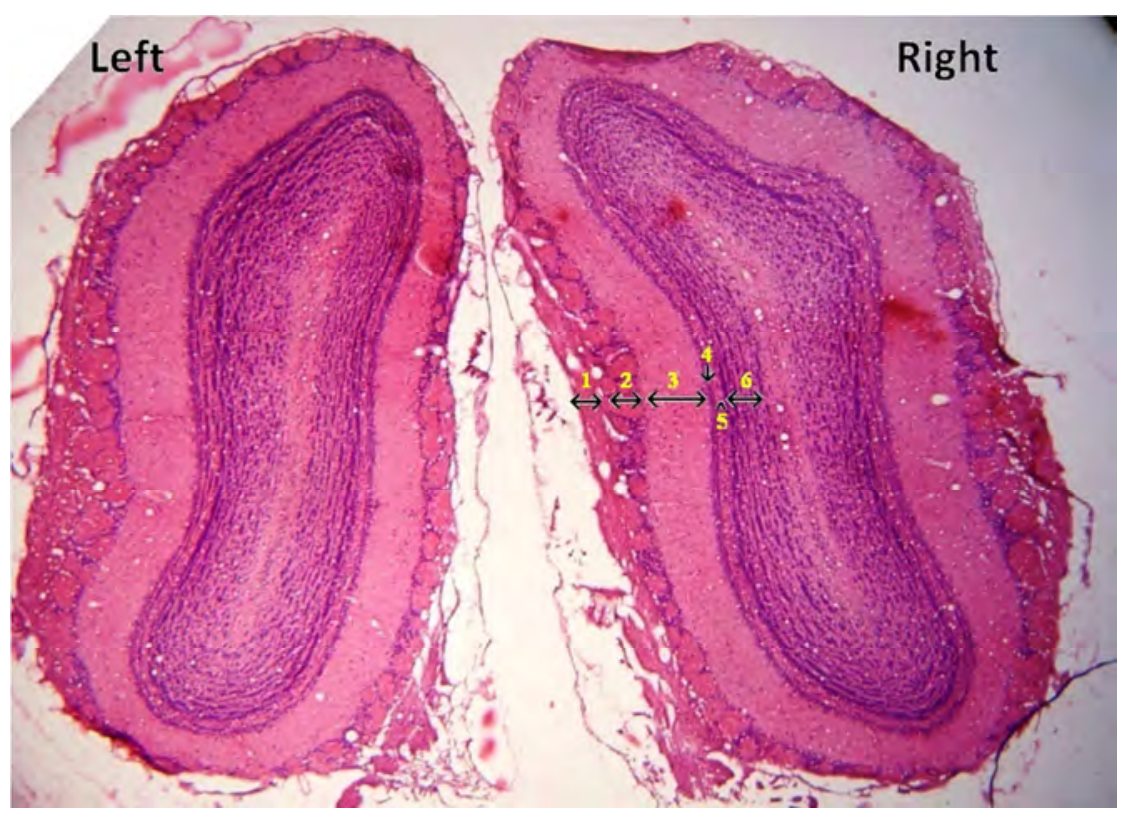

Figure 1. Photomicrograph of OBs from control showing their laminar structure: (1) ONL (2) GL (3) EPL (4) MCL (5) IPL and (6) GCL. Note that the OBs of both sides look almost similar in structure with minor asymmetry in their overall size and thickness of laminae; the left OB being smaller with thinner laminae. $H \&$ E stain. Initial magnification X 40 . 


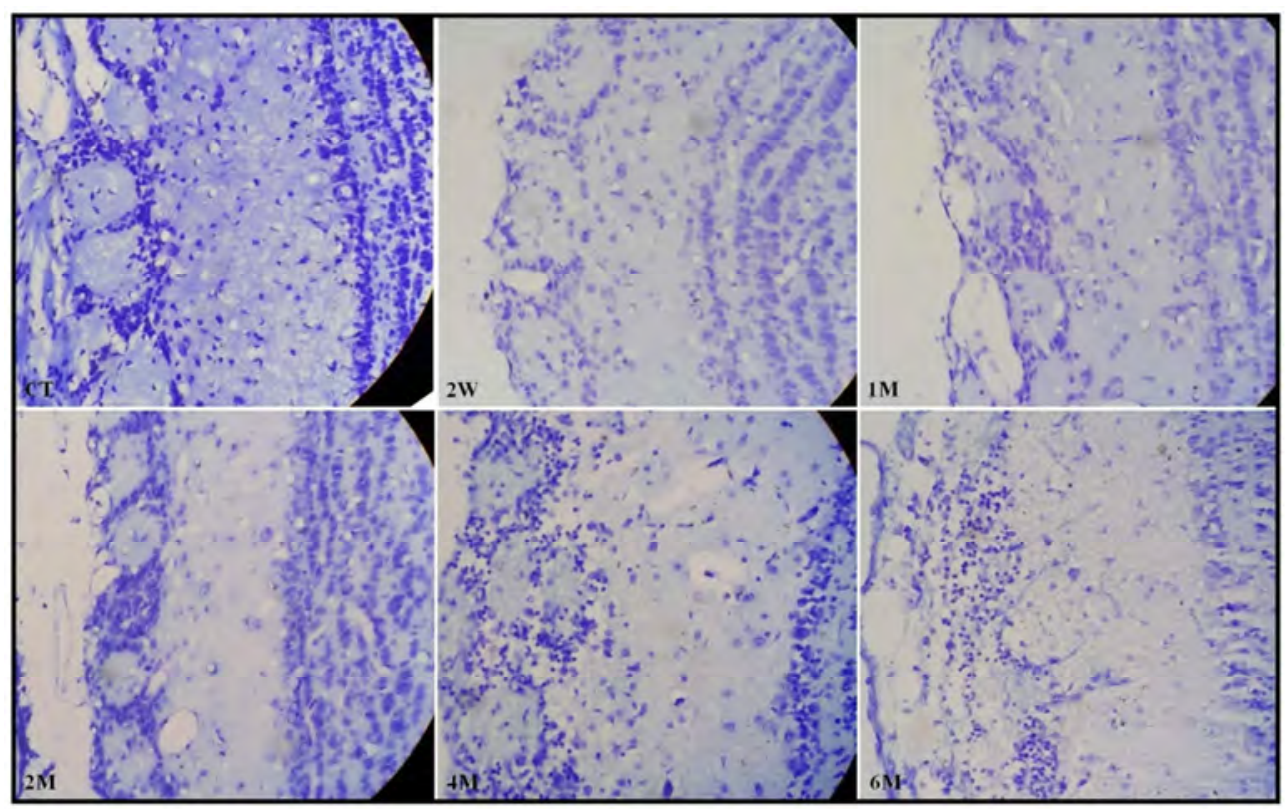

Figure 2. Photomicrograph of OBs showing the different diabetic groups. Lesser organized glomeruli were clearly observed in $4 M$ and $6 M$ diabetic group as compared to all other groups. CV stain. Initial magnification $X 400$.

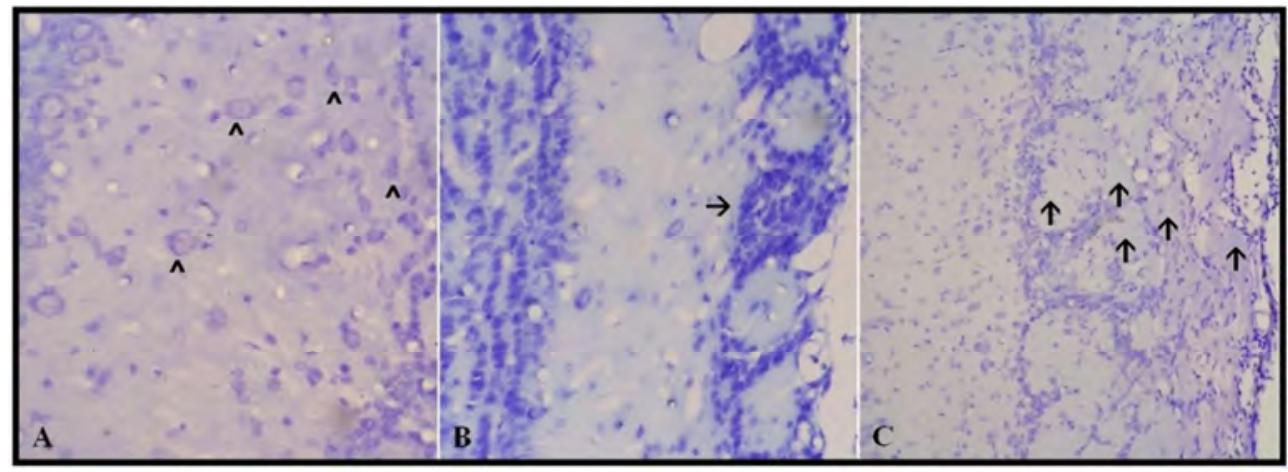

Figure 3. Photomicrograph of OBs from diabetic groups: (A) showing many misplaced mitral cells in EPL $(\wedge)$ in $1 M(B)$ showing hypercellular atypical glomerulus $(\rightarrow)$ in $2 M$ and $(C)$ showing multilayered glomeruli $(\uparrow)$, also in $2 M$. CV stain. Initial magnification X 400 .

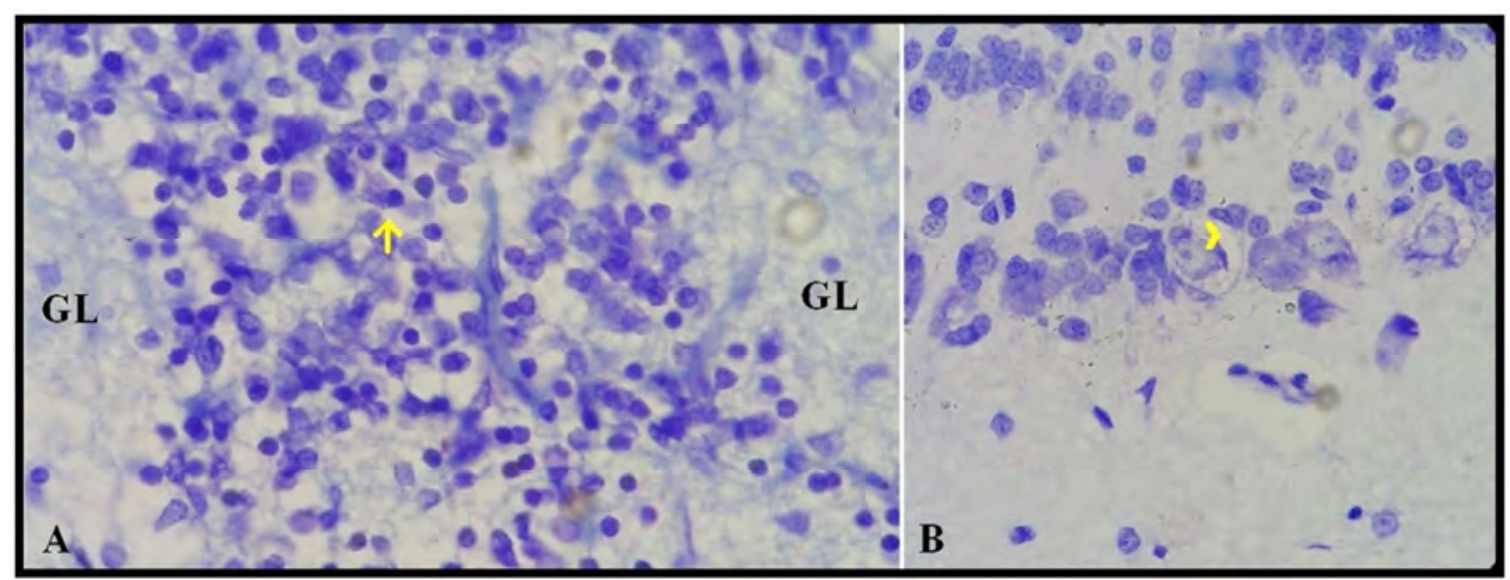

Figure 4. Photomicrograph of $6 \mathrm{M}$ diabetic group OBs (A) showing the aggregation of juxtaglomerular cells in inter glomerular space ( $\uparrow)$ and (B) showing the pericellular space around mitral cells (^). CV stain. Initial magnification X 400. 


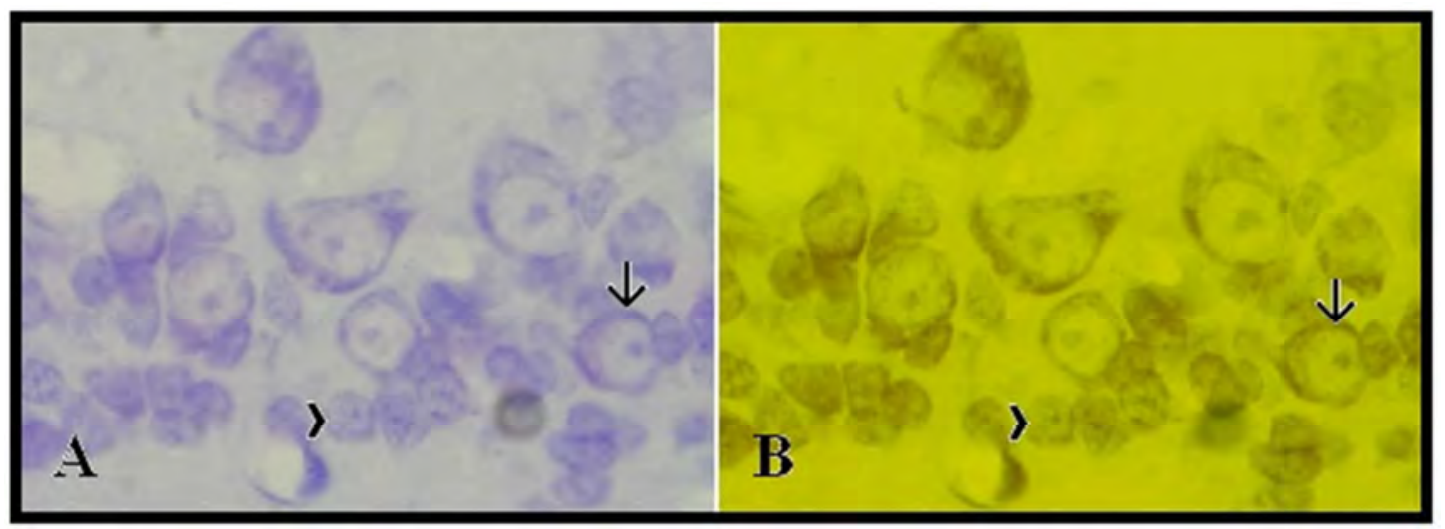

Figure 5. Microscopic images from OBs, showing both under visible light (A) and fluorescent (B): aggregation of mitral cells in 6M diabetic group. Lack of autofluorescence in perikaryia suggests absence of lipofuscin pigment. Initial magnification X 1000.

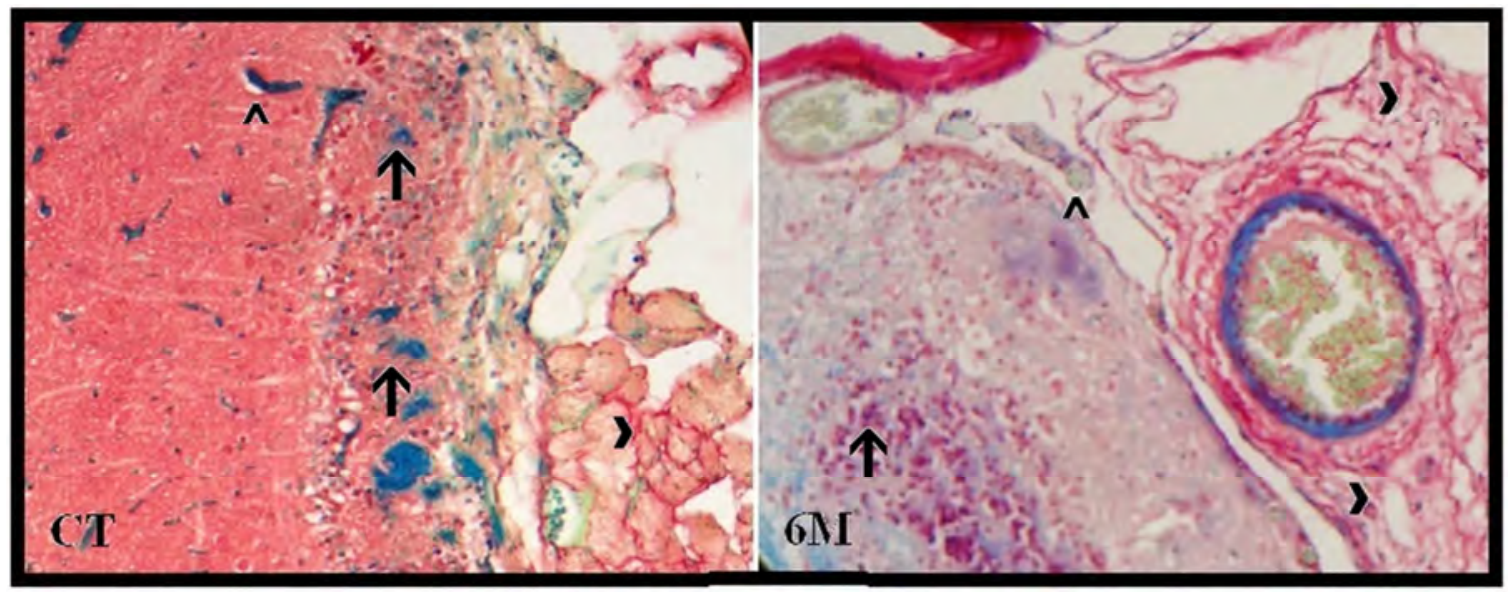

Figure 6. Photomicrograph showing the glomeruli $(\uparrow)$, blood vessel ( $\wedge)$, Collagen fibers (), red colour) seen around the OB and in the perivascular supporting tissue of control and 6M diabetic groups. Note the thickened numerous collagen fibers in 6M group. PSR \& LFB stain. Initial magnification X 200.

\subsubsection{Histomorphometry}

The histomorphometry of glomeruli revealed decrement of mean diameter of the glomeruli in diabetic group as compared with age- matched control. However it's significant $(\mathrm{P}<0.05)$ only in $4 \mathrm{M}$ and $6 \mathrm{M}$ diabetic groups as compared with to age-matched control group (Figure 7).

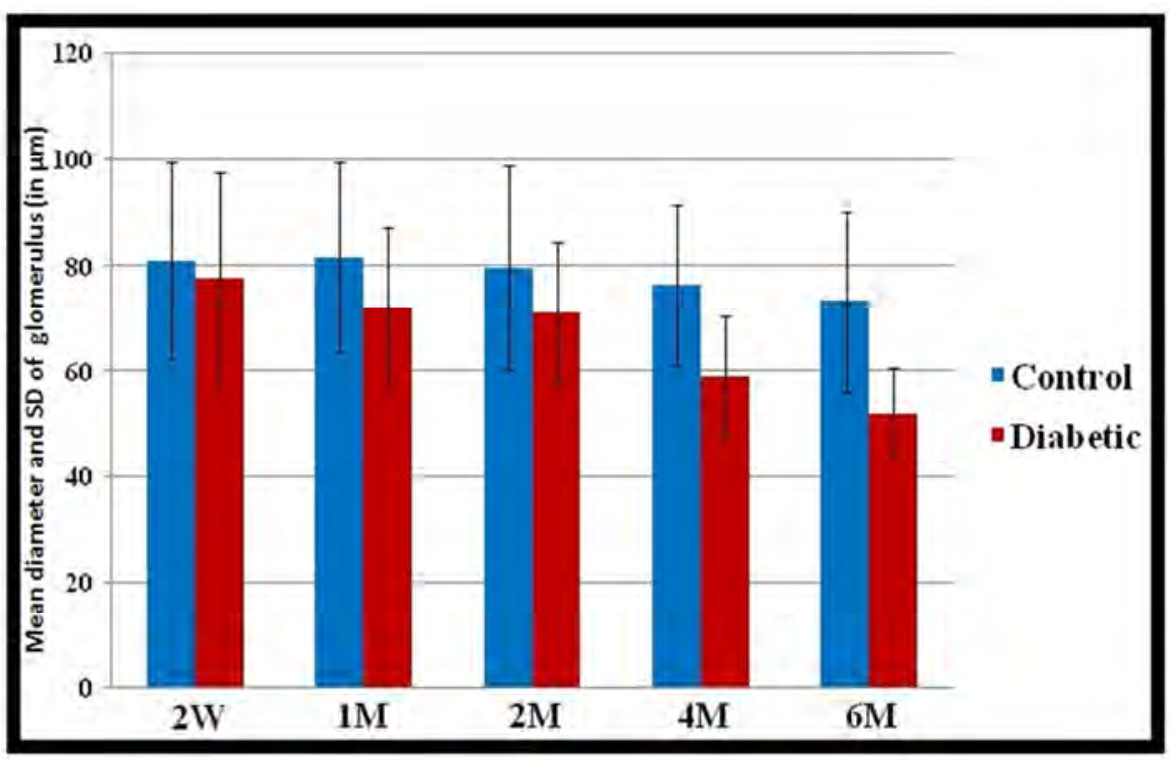

Figure 7. The mean diameter of glomeruli significantly $(P<0.05)$ reduced in $4 M$ and $6 M$ diabetic groups as compared with age-matched control group. 
Among 100 mitral cells having prominent nucleolus were selected to obtain mean diameter. Results show that in the $2 \mathrm{~W}$ and $1 \mathrm{M}$ diabetic groups the mean diameter of $\mathrm{MC}$ were less but not at significant $(\mathrm{P}>0.05)$ level. But in $2 \mathrm{M}, 4 \mathrm{M}$ and
$6 \mathrm{M}$ diabetic group the mean diameter decreases at significant level $(\mathrm{P}<0.05)$ as compared to age-matched control group (Figure 8).

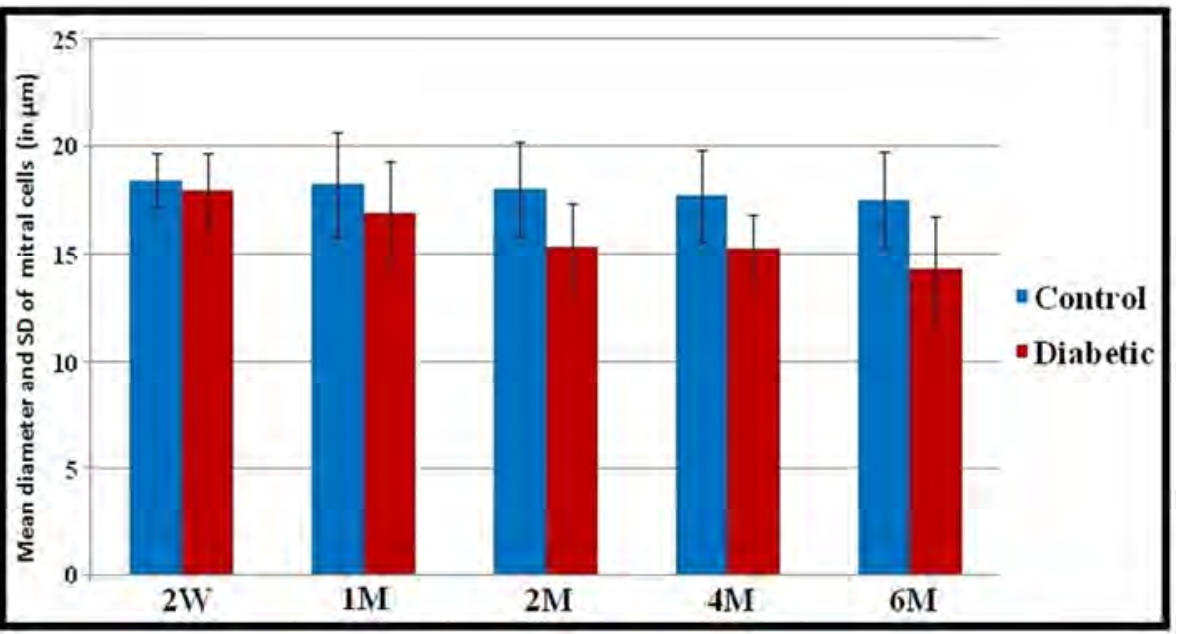

Figure 8. The mean diameter of mitral cells significantly $(P<0.05)$ reduced in $2 M, 4 M$ and $6 M$ diabetic groups as compared with age-matched control group.

\subsection{Biochemical Analysis}

The serum creatinine levels were significantly $(\mathrm{P}<0.05)$ increased in all diabetic group except $2 \mathrm{~W}$ diabetic group as compared to age-matched control group. However serum total protein levels significantly $(\mathrm{P}<0.05)$ decreases in all diabetic groups as compared to age matched control group (Table 1).

Table 1. In all diabetic groups the serum total protein levels significantly $(P<0.05)$ decreased compared to age matched control group. Serum creatinine levels were significantly $(P<0.05)$ increased in all diabetic groups except $2 \mathrm{~W}(P>0.05)$.

\begin{tabular}{|c|c|c|c|c|c|c|}
\hline Parameter & Group & $2 W$ & $1 \mathrm{M}$ & $2 M$ & $4 M$ & $6 M$ \\
\hline \multirow{2}{*}{ Serum total protein $(\mathrm{g} / \mathrm{dl})$} & Control & $5.97 \pm 0.04$ & $5.95 \pm 0.05$ & $5.99 \pm 0.03$ & $6.01 \pm 0.01$ & $5.98 \pm 0.05$ \\
\hline & Diabetic & $5.23 \pm 0.01$ & $5.12 \pm 0.03$ & $5.00 \pm 0.07$ & $4.05 \pm 0.03$ & $3.96 \pm 0.04$ \\
\hline \multirow{2}{*}{ Serum Creatinine $(\mathrm{mg} / \mathrm{dl})$} & Control & $0.43 \pm 0.02$ & $0.42 \pm 0.06$ & $0.45 \pm 0.05$ & $0.44 \pm 0.07$ & $0.43 \pm 0.04$ \\
\hline & Diabetic & $0.45 \pm 0.07$ & $0.63 \pm 0.08$ & $0.78 \pm 0.03$ & $0.93 \pm 0.09$ & $1.06 \pm 0.05$ \\
\hline
\end{tabular}

\section{Discussion}

Diabetes mellitus is a world's fastest growing common heterogeneous metabolic disorder of carbohydrate, fat and protein metabolism that has been shown to affect both peripheral and central nervous systems $[20,21]$ characterized by insufficient amounts of insulin, or in which tissues fail to respond appropriately to insulin, in terms of glucose resistance and glucose intolerance, which leads to hyperglycemia [22, 23 and 24]. In the long term, diabetes may lead to well-known potentially serious secondary complications in several organ systems especially those that are insulin insensitive organs like kidney, neurons and retina; however CNS disorders include alterations in neurotransmission, electrophysiological abnormalities, structural abnormalities and moderate disturbances of learning and memory [5, 25 and 26]. In Diabetes the reduction in body weight is primarily due to increased muscle wasting and due to loss of tissue proteins during release of amino acids for gluconeogenesis [27, 28]. Previous studies [29, 30 and 31] have also reported that body weight were reduced in diabetic group and this was found to be in agreement with present study that all diabetic groups maintained the hyperglycemic state throughout experimental periods and there was a progressive weight reduction in all diabetic groups, which reflected the increase in protein catabolism and add loss of tissue proteins in STZ-induced diabetic rats.

The OB is considered the primary centre of the olfactory pathway and relay station for processing odor sensation from olfactory epithelium [32]. In the current study, the right/left asymmetry could be easily observed (Figure 1). Asymmetry of OB is believed to be due to hypoplasia of smaller looking OB or else due to enlargement of apparently larger looking OB [33]. In the present study, structure and orientation of different lamina in the OB of adult albino rat in both control and experimental groups were found to be similar to those reported earlier [34] which are in agreement with the light microscopic observation of the current study. However, prolonged hyperglycemia induces structural changes in the olfactory bulb in the form of alteration in the normal laminar organization of $4 \mathrm{M}$ and $6 \mathrm{M}$ diabetic groups. This result is in 
agreement with those reported exposure of STZ-induced diabetes in rat [19] which may be due to irreversible damage of $\mathrm{OB}$ in experimentally induced neuro-toxic effect of hyperglycemia.

OB glomeruli are considered the first synaptic level of the olfactory pathway and the functional unit in olfactory information processing and sending information to the mitral cells [35]. Each glomerulus is surrounded by heterogeneous population of cells including a number of glial cells and juxtaglomerular neurons which include periglomerular cells, short axons and external tufted cells [36, 37]. In the current study, OB shows considerably decreases mean glomerular diameter of all diabetic group as compared with control. Decreased glomerular diameter in the present study is agreement with those reported by certain researchers [19] which indicate that $\mathrm{OB}$ is vulnerable to glucose neurotoxicity. Many studies suggested that hyperglycemia induced mitochondrial dysfunction and oxidative stress followed by formation of reactive oxygen species (ROS) that plays major role in hyperglycemia induced neurotoxicity [4]. The results of present study suggest the structural alteration of the OB glomeruli may also be due to hyperglycemia induced neurotoxicity. The atypical olfactory glomeruli are composed of an original part of olfactory bulb glomeruli whose functional significance in the processing of olfactory sensory information remains unknown [38]. In the current study $2 \mathrm{M}$ diabetic group showed some atypical OB glomeruli appear to be arranged in multiple layers (Figure $3 \mathrm{C}$ ) and it association with hyperglycemia could not be explained. Atypical hypercellular OB glomeruli were observed quite regularly in $2 \mathrm{M}, 4 \mathrm{M}$ and 6 diabetic groups. Interestingly such aggregation of cells could not be found in the available literature images and therefore warranting further studies for its functional significance. One distant possible explanation could be that since the subventricular zone in adult rat gives rise to new neurons which gets integrated in the olfactory bulb [39] and insulin signaling in the brain is implicated in the modification of proliferation, differentiation, and survival of neural progenitor cells, the occurrence of increasing number of atypical hypercellular olfactory glomeruli appears to be somehow linked with diabetes-induced abnormalities of neural stem cells as well as diabetes-induces olfactory deficits [40].

Mitral cells are the largest and prominent neuron in the OB [41]. The present study showed significant decreases in the mean diameter of mitral cell in $\mathrm{OB}$ of $2 \mathrm{M}, 4 \mathrm{M}$ and $6 \mathrm{M}$ diabetic groups as compared with age-matched control group. Some studies suggested that the size of the mitral cells deceases with advancement of age [41, 42]. Considering the notion that prolonged diabetes increases the ageing process, it is quite likely that both diabetes and ageing may affect the size of the mitral cell both in an independently and synergistic manner as appears in the current study. In this study, some mitral cells have shown perineuronal spaces similar to those shown by some investigators in sensory ganglia [43, 44] and mitral cells [45]. That may due to either shrinking or apoptosis on progression of hyperglycemic state was also comparable to some of the finding in the present study. In the present study, only few mitral cells appear to exhibit chromatolytic changes of Nissl substance in the form of reduced basophilia, which were notice with advancement of hyperglycemic state in diabetic groups but in control group these types of mitral cells were only occasionally seen. In other study [45] reported that in mitral and pyramidal cells revealed reduced basophilia and dispersion of Nissl substance, in aged olfactory bulb. However one researcher suggested it as an evidence of irreparable damage to neurons [46]. Lipofuscin pigment (Senile pigment) is the undegradable oxidized protein and which is described to be one of the typical features of post-mitotic cells in aged olfactory and mitral cells [47, 48] and also in sympathetic ganglia [49]. In our present study lipofuscin pigment could not located even in chronic diabetic rats. Lipofuscin pigment show autofluorescent property with blue light [50]. Diabetes is said to increases accumulation of lipofuscin pigments in mitral or tufted cells [51], in sensory [52] and sympathetic neuron [53] which could not be confirmed in the current study. However the perikarya of mitral cells showed low grade yellow fluorescence in the region occupied by fine Nissl substance (Figure 5).

In the current study, PSR and LFB stained sections from the control groups of OB revealed thin collagen fibers around the $\mathrm{OB}$ and major blood vessels but in the $6 \mathrm{M}$ diabetic group of $\mathrm{OB}$, the collagen fibers were of remarkable thickness around the $\mathrm{OB}$ and major blood vessels possibly indicator of progressive fibrosis. Some researches demonstrating AGE and RAGE synergy increases expression of TGF- $\beta$ and devoted to the progression of submesothelial fibrosis and neoangiogenesis [54] and development of fibrosis in a diabetic heart by PKC- $\beta$ and p38 mitogen activated protein kinase expression in redox reaction [55]. Comparison of these with current observation suggests that the hyperglycemia accelerates fibrosis.

Creatinine is an amino acid derivative and it is cleared by tubular secretion [56]. Impaired kidney function in diabetic nephropathy exhibits an abnormal high level of serum creatinine. However serum creatinine, have been considered significant biomarker of diabetic nephropathy. An increased urea concentration in diabetic rats is also associated with greater protein catabolism [57]. The present study also revealed that high serum creatinine level in all diabetic groups is parallel to the severity of hyperglycemia. This result demonstrated a positive correlation between hyperglycaemia and the development of nephropathy. However in our results elevation of serum creatinine were consistent with the reduction in the total serum protein levels observed in the STZ-induced diabetic rats relating the hyperglycemia to a low grade inflammatory process [58]. Similar finding has been shown in another similar study [59, 60 and 61].

\section{Conclusion}

Based on histopathological, histomorphological and 
biochemical findings it is concluded that prolonged hyperglycemic state leads to increased serum creatinine level and decreased serum total protein. It is also associated with reduced mean diameter of glomeruli and mitral cells, frequent occurrence of misplaced mitral cells and hypercellular glomeruli and added thickening of collagen fibers around OB and blood vessels. Therefore, it appears that one of the important contributory factors in development of olfactory dysfunction in chronic diabetes might be the hyperglycemia-induced neuronal cytotoxicity and macro vascular alteration induced subtle $\mathrm{OB}$ laminar organization.

\section{Acknowledgements}

The authors would like to gratefully acknowledge all kinds of support and co-operation received from Department of Anatomy, and Neuroanatomy laboratory, JN Medical College, Aligarh Muslim University, Aligarh.

\section{References}

[1] Ozougwu JC, Obimba KC, Belonwu CD, Unakalamba CB. "The pathogenesis and pathophysiology of type 1 and type 2 diabetes mellitus". Journal of Physiology and Pathophysiology. 2013; 4: 46-57.

[2] Kangralkar VA, Patil SD, Bandivadekar RM. "Oxidative stress and diabetes": a review. International Journal of Pharmaceutical Applications. 2010; 1: 38-45.

[3] Ceriello A, Motz E. "Is oxidative stress the pathogenic mechanism underlying insulin resistance, diabetes, and cardiovascular disease? The common soil hypothesis revisited". Arteriosclerosis, Thrombosis, and Vascular Biology. 2004; 24: 816-823.

[4] Tomlinson DR, Gardiner NJ. "Glucose Neurotoxicity". Nature Publishing Group. 2008; 9: 36-45.

[5] Guven A, Yavuz O, Cam M, Comunoglu C, Sevinc O. "Central nervous system complications of diabetes in streptozotocininduced diabetic rats: a histopathological and immunohistochemical examination". International Journal of Neuroscience. 2009; 119: 1155-1169.

[6] Rudchenko A, Akude E, Cooper E. "Synapses on sympathetic neurons and parasympathetic neurons differ in their vulnerability to diabetes". Journal of neuroscience. 2014; 34: 8865-8874.

[7] Grazyna L, Thomas N, Claes-Goran O, Vladimer D, Cesare P. "Type 2 diabetes-induced neuronal pathology in the piriform cortex of the rat is reversed by the GLP-1 receptor agonist exendin-4". Oncotarget. 2016; 7: 5865-5876.

[8] Srinivasan S, Stevens M, Wiley JW. 2000. Diabetic Peripheral Neuropathy- Evidence for Apoptosis and Associated Mitochondrial Dysfunction. Diabetes. 2000; 49: 1932-1938.

[9] Spielman AL. "Chemosensory function and dysfunction". Critical Reviews in Oral Biology and Medicine. 1998; 9: 267-291.

[10] Hillson R. 2014. "Taste and smell in diabetes". Practical diabetes. 2014; 31: 269-271.
[11] Standring S, Ellis H, Healy JC, Johnson D, Williams A, Collins P. "Gray's anatomy: the anatomical basis of clinical practice". 40th ed. London: Churchill Livingstone, Elsevier. 2008; p. 1030.

[12] Marfaing-Jallat P, Portha B, Penicaud L. "Altered conditioned taste aversion and glucose utilization in related brain nuclei of diabetic GK rats". Brain research bulletin. 1995; 37: 639-643.

[13] Weinstock RS, Wright HN, Smith DU. "Olfactory dysfunction in diabetes mellitus". Physiology and Behavior. 1993; 53: 1721 .

[14] Naka A, Riedl M, Luger A, Hummel T, Mueller CA. "Clinical significance of smell and taste disorders in patients with diabetes mellitus". European Oto-Rhino-Laryngology. 2010; 267: 547-550.

[15] Patterson DS, Turner P, Smart JV. "Smell threshold in diabetes mellitus". Nature. 1966; 209: 625.

[16] Bramerson A, Johansson L, Ek L, Nordin S, Bende M.. "Prevalence of olfactory dysfunction: the skovde populationbased study". The Laryngoscope. 2004; 114: 733-737.

[17] Thiebaud N, Johnson MC, Butler JL, Bell GA, Ferguson KL, Fadool AR, Fadool JC, Gale AM, Gale DS, Fadool DA. "Hyperlipidemic diet causes loss of olfactory sensory neurons, reduces olfactory discrimination, and disrupts odor-reversal learning”. The Journal of neuroscience. 2014; 34: 6970-6984.

[18] Dennis JC, Coleman ES, Swyers SE, Moody W, Wright JC, Judd R, Zhong Q, Morrison EE. "Changes in mitotic rate and GFAP expression in the primary olfactory axis of Streptozotocin-induced diabetic rats". Journal of Neurocytology. 2005; 34: 3-10.

[19] Gao LF, Huang MM, Lei H. "Diffusion Abnormality in Olfactory Bulbs of Type-I Diabetic Rats". Proceedings of the International Society for Magnetic Resonance in Medicine Scientific Meeting and Exhibition. 2011; 19: 2302.

[20] Gardoni F, Kamal A, Bellone C, Biessels GJ, Ramakers GMJ, Cattabeni F, Gispen WH, Luca MD. "Effects of streptozotocin-diabetes on the hippocampal NMDA receptor complex in rats". Journal of Neurochemistry. 2002; 80: 438447.

[21] Shanmugam KR, Mallikarjuna K, Kesireddy N, Reddy KS. "Neuroprotective effect of ginger on anti-oxidant enzymes in streptozotocin-induced diabetic rats". Food and chemical toxicology. 2011; 30: 893-897.

[22] Doddigarla Z, Parwez I, Abidi S, Ahmad J. Effect of Melatonin and Chromium Picolinate Administration to High Carbohydrate Diet-Fed Male Wistar Rats. Journal of Molecular and Genetic Medicine. 2017; 11: 1-7.

[23] Liu CC, Hu J, Tsai CW, Yue M, Melrose HL, Kanekiyo T, Bu GJ. "Neuronal LRP1 regulates glucose metabolism and insulin signaling in the brain". The Journal of Neuroscience 2015; 35: $5851-5859$.

[24] American Diabetes Association. 2. "Classification and diagnosis of diabetes". Diabetes care. 2015; 38: 8-16.

[25] Helkala EL, Niskanen L, Viinamaki H, Partanen J, Uusitupa M. "Short-term and long-term memory in elderly patients with NIDDM". Diabetes Care. 1995; 18: 681-685. 
[26] Selim SA, Selim AO. "Effect of streptozotocin-induced diabetes mellitus on the cerebellar cortex of adult male albino rats": histological and immunohistochemical study. The Egyptian Journal of Histology. 2013; 36: 103-113.

[27] Air EL, Strowski MZ, Benoit SC, Conarellosl, Salituro GM, Guan XM, Liu K, Woods SC, Zhang BB. "Small molecule insulin mimetics reduce food intake and body weight and prevent development of obesity". Nature Medicine. 2002; 8: $179-183$.

[28] Jain D, Bansal MK, Dalvi R, Upganlawar A, Somani R. "Protective effect of diosmin against diabetic neuropathy in experimental rats". Journal of Integrative Medicine. 2014; 12: $35-41$

[29] Doddigarla Z, Parwez I, Abidi S, Ahmad J. "Effect of Chromium Picolinate and Melatonin either in Single or in a Combination in Alloxan Induced Male Wistar Rats". Journal of Biomedical Sciences. 2016; 6: 1-7.

[30] Elsy B, Maheshwari V, Khan AA. "Effects of $d \alpha$-Tocopherol on Progression of Reepithelialization, Matrix Remodeling and Appearance of Epidermal Appendages in Secondary Skin Wounds of Diabetic Rats". Journal of Dermatology and Clinical Research. 2017; 4: 1-7.

[31] Faizal PAM, Khan AA, Elsy B. "Effect of experimental hyperglycemia on the trigeminal ganglia of albino rats". International Journal of Health Sciences and Research. 2017; 7: 191-198.

[32] Kosaka K, Kosaka T. "Synaptic organization of the glomerulus in the main olfactory bulb: compartments of the glomerulus and heterogeneity of the periglomerular cells". Anatomical science international. 2005; 80: 80-90.

[33] Dilkash NA, Khan AA. "Asymmetry due to anomalous unilateral enlargement of olfactory bulb in Albino rat": A case report. Current Neurobiology. 2010; 1: 113-117.

[34] Mousa AM, Shehab AA. "The effect of manganese on the olfactory bulb of adult male albino rat and the role of meloxicam": A histological and immunohistochemical study. Journal of Microscopy and Ultrastructure. 2015; 31: 08-18.

[35] Shipley MT, Ennis M. "Functional organization of olfactory system". Journal of Neurobiology. 1996; 30: 123-176.

[36] Pinching AJ, Powell TP. "The neuron types of the glomerular layer of the olfactory bulb". Journal of cell science. 1971; 9: 305-345.

[37] Homma R, Kovalchuk Y, Konnerth A, Cohen LB, Garaschuk O. "In vivo functional properties of juxtaglomerular neurons in the mouse olfactory bulb". Frontiers in Neural Circuits. 2013; $7: 1-23$.

[38] Zheng LM, Ravel N, Jourdan F. "Topography of centrifugal acethvtcholinesterase-positive fibres in the olfactory bulb of the rat: evidence for original projections in atypical glomeruli". Neuroscience. 1987; 23: 1083-1093.

[39] Whitman MC, Greer CA. Adult neurogenesis and the olfactory system. Prog Neurobiol. 2009; 89: 162-175.

[40] Jing YH, Qi CC, Yuan L, Liu XW, Gao LP, Yin J. Adult neural stem cell dysfunction in the subventricular zone of the lateral ventricle leads to diabetic olfactory defects. Neural. Reg. Res. 2017; 12: 1111-1118.
[41] Bhatnagar KP, Kennedy RC, Baron G, Greenberg RA. "Number of mitral cells and the bulb volume in the aging human olfactory bulb": a quantitative morphological study. Anatomical record. 1987; 218: 73-87.

[42] Hinds JW, Mc Nelly NA. Aging of the rat olfactory bulb: growth and atrophy of constituent layers and changes in size and number of mitral cells. The Journal of Comparative Neurology. 1977; 72: 345-367.

[43] Malak HW, Saleh SI, Salah El Din RA, Hamid HFA. "Histological and immunohistochemical study on the consequences of acute glycemic level alteration on the dorsal root ganglia and sciatic nerve integrity in neonatal albino rats". Egyptian Journal of Histology. 2015; 38: 332345 .

[44] Faizal MPA, Khan AA. "Impact of Experimental Hyperglycemia on the Lumbosacral Dorsal Root Ganglia of Albino Rats". International Journal of Medical and Health Sciences. 2017; 6: 158-164.

[45] Eltony SA, Elgayar SA. "Histological study on effect of Nigella sativa on aged olfactory system of female albino rat". Romanian Journal of Morphology and Embryology. 2014; 55: 325-334.

[46] Nandy K. "Neuronal degeneration in aging and after experimental injury". Experimental Gerontology Journal. 1972; 7: 303-311.

[47] Keller JN, Dimayuga E, Chen Q, Thorpe J, Gee J, Ding Q. "Autophagy, proteasomes, lipofuscin, and oxidative stress in the aging brain". International Journal of Biochemistry and Cell Biology. 2004; 36: 2376- 2391.

[48] Terman A, Brunk UT. "Aging as a catabolic malfunction". International Journal of Biochemistry and Cell Biology. 2004; 36: $2365-2375$.

[49] Young B, O'Dowd G, Woodford P. "Wheater's Functional Histology"- A text and colour atlas. Churchill living stone $6^{\text {th }}$ edition. Reprint 2016; 139 p

[50] Katz ML, Robison WG Jr. "What is lipofuscin? Defining characteristics and differentiation from other autofluorescent lysosomal storage bodies". Archives of Gerontology and Geriatrics. 2002; 34: 169-184.

[51] Vaishnav RA, Getchell ML, Poon HF, Barnett KR, Hunter SA, Pierce WM, Klein JB, Butterfield DA, Getchell TV. "Oxidative stress in the aging murine olfactory bulb: redox proteomics and cellular localization". Journal of Neuroscience Research. 2007; 85: 373-385.

[52] Sugaya A, Sugimioto H, Mogi N, Tsujigami H, Deguchi S. "Experimental diabetes accelerates accumulation of fluorescent pigments in rat trigeminal neurons". Brain Research. 2004; 27: 132-134.

[53] Schmidt RE, Plurad SB, Parvin CA, Roth KA. "Effect of Diabetes and Aging on Human Sympathetic Autonomic Ganglia”. Americal Journal of Pathology. 1993; 143: 143153.

[54] De Vriese AS, Flyvbjerg A, Mortier S, Tilton RG, Lameire $\mathrm{NH}$. "Inhibition of the interaction of AGE-RAGE prevents hyperglycemia-induced fibrosis of the peritoneal membrane". Journal of American Society of nephrology. 2003; 14: 2109-2118. 
[55] Olubunmi A, Adebiyi, Oluwafeyisetan O, Adebiyi, Peter MO, Owira. "Naringin Reduces Hyperglycemia-Induced Cardiac Fibrosis by Relieving Oxidative Stress". Plos One. 2016; 11: 115 .

[56] Ronco C, Grammaticopoulos S, Rosner M, Decal M, Soni S, Lentini P. "Oliguria, Creatinine and other biomarkers of acute kidney injury". Contributions Nephrol. 2010; 164: 118-27.

[57] Ceriello A, Morocutti A, Franceschina M, Quagliaro L, Moro M, Damante G. "Defective intracellular Antioxidant Enzyme Production in Type 1 Diabetic Patients With Nephropathy". American Diabetic association. 2000; 49: 2170-2177.

[58] Sjoholm A, Nystrom T. "Inflammation and the etiology of type 2 diabetes". Diabetes/metabolism research and reviews. 2006; 22: 04-10.
[59] Punithavathi VR, Anuthama R, Prince PS. "Combined treatment with naringin and vitamin $\mathrm{C}$ ameliorates streptozotocin-induced diabetes in male wistar rats". Journal of Applied Toxicology. 2008; 28: 806-813.

[60] Almeida DATD, Braga CP, Novelli ELB, Fernandes AAH. "Evaluation of Lipid Profile and Oxidative Stress in STZ Induced Rats Treated with Antioxidant Vitamin". Brazilian Archives of Biology and Technology. 2012; 55: 527-536.

[61] Elsy B, Maheshwari V, Khan AA. "Effects of $d \alpha$-Tocopherol on Progression of Reepithelialization, Matrix Remodeling and Appearance of Epidermal Appendages in Secondary Skin Wounds of Diabetic Rats". Journal of Dermatology and clinical research. 2016; 4: 1-7. 